OPEN ACCESS

Edited by:

Pieter de Lange,

Università degli Studi della Campania

"Luigi Vanvitelli" Caserta, Italy

Reviewed by:

Gabriela Brenta,

Dr. César Milstein Care Unit,

Argentina

Salvatore Benvenga,

Università degli Studi di Messina, Italy

*Correspondence:

Sandra Ghelardoni

sandra.ghelardoni@med.unipi.it

Specialty section: This article was submitted to

Thyroid Endocrinology,

a section of the journal

Frontiers in Endocrinology

Received: 20 March 2018

Accepted: 14 May 2018

Published: 30 May 2018

Citation:

Sacripanti G, Nguyen NM, Lorenzini L, Frascarelli S, Saba A, Zucchi R and Ghelardoni S (2018) 3,5-Diiodo-I-Thyronine Increases Glucose Consumption in Cardiomyoblasts Without Affecting the Contractile Performance in Rat Heart.

Front. Endocrinol. 9:282. doi: 10.3389/fendo.2018.00282

\section{3,5-Diiodo-L-Thyronine Increases Glucose Consumption in Cardiomyoblasts Without Affecting the Contractile Performance in Rat Heart}

\author{
Ginevra Sacripanti, Nhat Minh Nguyen, Leonardo Lorenzini, Sabina Frascarelli, \\ Alessandro Saba, Riccardo Zucchi and Sandra Ghelardoni*
}

Dipartimento di Patologia Chirurgica, Medica, Molecolare e dell'Area Critica, University of Pisa, Pisa, Italy

3,5-diiodo-L-thyronine (T2) is an endogenous derivative of thyroid hormone that has been suggested to regulate energy expenditure, resting metabolic rate and oxygen consumption with a mechanism that involves the activation of mitochondrial function. In this study, we focused on the cardiac effects of $\mathrm{T} 2$, which have been poorly investigated so far, by using both in vitro and ex vivo models. As a comparison, the response to T3 and T4 was also determined. Rat cardiomyoblasts (H9c2 cells) were used to determine T2, T3, and T4 uptake by high-performance liquid chromatography-tandem mass spectrometry. In the same experimental model, MTT test, crystal violet staining, and glucose consumption were investigated, using T2 concentrations ranging from 0.1 to $10 \mu \mathrm{M}$. To assess cardiac functional effects, isolated working rat hearts were perfused with T2, T3, or T4 in Krebs-Ringer buffer, and the hemodynamic variables were recorded. T2 was taken up by cardiomyoblasts, and in cell lysate T2 levels increased slowly over time, reaching higher concentrations than in the incubation medium. T2 significantly decreased MTT staining at $0.5-10 \mu \mathrm{M}$ concentration $(P<0.05)$. Crystal violet staining confirmed a reduction of cell viability only upon treatment with $10 \mu \mathrm{M}$ T2, while equimolar T3 and T4 did not share this effect. Glucose consumption was also significantly affected as indicated by glucose uptake being increased by 24 or $35 \%$ in cells exposed to 0.1 or $1.0 \mu \mathrm{M}$ T2 $(P<0.05$ in both cases). On the contrary, T3 did not affect glucose consumption which, in turn, was significantly reduced by 1 and $10 \mu \mathrm{M}$ T4 ( -24 and $-41 \%$ vs control, respectively, $P<0.05$ and $P<0.01$ ). In the isolated perfused rat heart, $10 \mu \mathrm{M}$ T2 produced a slight and transient reduction in cardiac output, while T3 and T4 did not produce any hemodynamic effect. Our findings indicate that $\mathrm{T} 2$ is taken up by cardiomyoblasts, and at 0.1-1.0 $\mu \mathrm{M}$ concentration it can modulate cardiac energy metabolism by increasing glucose consumption. Some evidence of toxicity and a transient impairment of contractile performance are observed only at $10 \mu \mathrm{M}$ concentration. These effects appear to be specific for T2, since they are not reproduced by T3 or T4.

Keywords: T2, heart perfusion, cardiomyoblasts, glucose consumption, T2 uptake 


\section{INTRODUCTION}

3,5-Diiodo-L-thyronine (T2), an endogenous metabolite of thyroid hormones $(\mathrm{TH})$, has been described as a peripheral mediator of several TH metabolic effects (1). Although conversion of 3,5,3'-triiodothyronine (T3) to T2 has not yet been demonstrated in vitro, indirect evidence indicates that $\mathrm{T} 2$ is, indeed, formed from $\mathrm{T} 3$ in vivo, through deiodination (2). Both $\mathrm{T} 2$ and $\mathrm{T} 3$ increase resting metabolic rate, but the response to $\mathrm{T} 2$ shows a more rapid onset (3). These findings have induced to hypothesize that T2 might mediate some of the short-term effects of TH and that it might be involved, like T3, in physiological processes leading to increased energy expenditure (3). While the response to T3 was principally mediated by nuclear receptors, the effects of $\mathrm{T} 2$ were independent of protein synthesis (4) suggesting that they were probably due to a direct interaction with mitochondria.

Several reports have shown that, in rats, acute or chronic T2 administration causes significant changes in mitochondrial activities, stimulating fatty acid oxidation, and decreasing hepatic lipid accumulation (5-9). At the dosage $0.25 \mu \mathrm{g} / \mathrm{g}$ body weight for 4 weeks i.p. (10), T2 prevented body weight gain in rats fed with a high-fat diet, without inducing T3-related undesirable side effects, namely tachycardia, cardiac hypertrophy, and decreased TSH levels. In this models, T2 stimulated mitochondrial uncoupling, decreased ATP synthesis, and increased hepatic fatty acid oxidation rate, thus counteracting obesity. Additionally, T2 induced biochemical and structural shifts toward glycolytic myofibers and prevented an increase in serum triglycerides and cholesterol $(10,11)$. On the whole, it has been clearly established that T2 exerts hepatic antilipidemic effects, but its physiological relevance in skeletal and cardiac muscle is still unclear. In skeletal muscle, Moreno et al. (12) reported increased insulin sensitivity upon T2 administration, particularly increased protein kinase B phosphorylation, and sarcolemmal GLUT4 accumulation. In another investigation, T2 induced proton leak in skeletal muscle mitochondria obtained from hypothyroid rats (13).

Chronic administration of a low T2 dosage to two healthy volunteers increased resting metabolic rate and decreased body weight, by inducing a reduction in steatosis and in the total serum cholesterol levels, without affecting cardiac function (14). Conversely, a recent study reported that, at a higher dosage $(2.5 \mu \mathrm{g} / \mathrm{g}), \mathrm{T} 2$ administration exerted thyromimetic effects, since it induced cardiac hypertrophy and an overall genomic effect similar to that produced by the TH (T3) (15). However, the cardiac effects of $\mathrm{T} 2$ have not been extensively investigated so far. Therefore, in this study we explored the functional, metabolic, and toxic effects of T2 using both in vitro and ex vivo models of cardiac preparations.

\section{MATERIALS AND METHODS}

\section{Chemicals}

H9c2 (2-1) rat cardiomyoblast cell lines were obtained from American Type Culture Collection (Manassas, VA, USA). [ $\left.{ }^{3} \mathrm{H}\right]-$ ryanodine was obtained from New England Nuclear (Milan, Italy). Ryanodine was purchased from Abcam, UK. Unless otherwise specified, all reagents were obtained from Sigma-Aldrich (St. Louis, MO, USA). Solvents for HPLC-MS/MS measurements were HPLC-grade, and the other chemicals were reagentgrade.

\section{Cell Culture and Treatment}

Rat cardiomyoblasts (cell line H9c2) were cultured in DMEM supplemented with $10 \%$ (vol/vol) FBS, $1 \mathrm{mM}$ pyruvate, $100 \mathrm{U} / \mathrm{ml}$ penicillin, and $100 \mu \mathrm{g} / \mathrm{ml}$ streptomycin at $37^{\circ} \mathrm{C}$ in a humidified atmosphere containing $5 \% \mathrm{CO}_{2}$ and subcultured before confluence. To assess glucose uptake, $\mathrm{H} 9 \mathrm{c} 2$ were seeded in six-well plate $\left(5 \times 10^{5}\right.$ cells/well), grown to $80 \%$ of confluence with standard medium and washed twice with PBS before treatment. Then, cells were exposed for $4 \mathrm{~h}$ to exogenous T2 $(0.1-10 \mu \mathrm{M})$ in $1 \mathrm{ml}$ of the same DMEM base (phenol free) supplemented with $0.7 \mathrm{mg} / \mathrm{ml}$ glucose. Control cells were incubated with DMEM containing the same volume of vehicle. Cell culture medium was then collected and glucose concentration was evaluated in medium with a spectrophotometric assay kit (Sigma-Aldrich). Hexokinase activity was assessed in cell lysate with a colorimetric assay kit (BioVision, Milpitas, CA, USA). Enzyme activity was evaluated following kit protocol. The absorbance was read at $450 \mathrm{~nm}$. Metabolite concentrations were referred to the total protein content of whole-cell lysates (16).

\section{Uptake of T2 and HPLC-MS/MS Assay Technique}

The experiments aimed at evaluating hormone uptake were performed as previously described, with minor modifications (17). Briefly, cells (H9c2) were seeded into 24-well plate $\left(8.5 \times 10^{4}\right.$ cells/well) and grown to $80 \%$ confluence. At the start of each experiment, the culture medium was removed, and after washing with PBS, fresh medium containing $100 \mathrm{nM}$ T2, $50 \mathrm{nM}$ T3 or T4 was added. The plate was returned to a humidified atmosphere of $5 \% \mathrm{CO}_{2}$ at $37^{\circ} \mathrm{C}$, and the medium was removed from each well at specific time points and frozen at $-80^{\circ} \mathrm{C}$ until extraction. At the end of the experiment, cell plates were washed with PBS and frozen. Cell lysis was carried out using $100 \mu \mathrm{l}$ of $0.1 \mathrm{M} \mathrm{NaOH}$ and samples were neutralized by adding $10 \mu \mathrm{l}$ of $1 \mathrm{M} \mathrm{HCl}$. After $\mathrm{pH}$ neutralization, $390 \mu \mathrm{MeOH}$ were added and samples collected and centrifuged for $10 \mathrm{~min}$ at $14,000 \times \mathrm{g}$, and the supernatant was evaporated under $\mathrm{N}_{2}$ at $40^{\circ} \mathrm{C}$. Dry samples were then reconstituted using $50 \mu \mathrm{l}$ of water/acetonitrile (70:30 by volume) containing $0.1 \%$ formic acid, and analyzed using HPLC coupled tandem mass spectroscopy, as elsewhere described (17). Cell culture medium was extracted using a liquid-liquid method: $1 \mathrm{ml}$ of methyl tert-butyl ether was added and then the mixture was vigorously shaken for $30 \mathrm{~s}$. Then the mixture was briefly spinned at $14,000 \times g$ to completely separate the organic and aqueous phases. The organic phase was then collected and the extraction process was repeated twice. At the end of the procedure, the collected organic phases were evaporated under $\mathrm{N}_{2}$ at $40^{\circ} \mathrm{C}$. Dry samples were then reconstituted using $50 \mu \mathrm{l}$ of water/ acetonitrile ( $70: 30$ by volume) containing $0.1 \%$ formic acid and analyzed using HPLC coupled tandem mass spectroscopy assay, as detailed below. The positive ion mode method included: ionspray 
voltage, $5.00 \mathrm{kV}$; gas source 1 , 70; gas source 2, 55; turbo temperature, $650^{\circ} \mathrm{C}$; entrance potential, $10 \mathrm{~V}$; collision-activated dissociation gas pressure, $12 \mathrm{mPa}$. HPLC runs were based on the following mobile-phase gradient: solvent $\mathrm{A}$, methanol/acetonitrile $1: 4$, containing $0.1 \%$ formic acid; solvent $\mathrm{B}$, water containing $0.1 \%$ formic acid. The gradient started at $5 \% \mathrm{~A}$ increasing to $65 \%$ at $8.5 \mathrm{~min}$, then to $100 \%$ at $9 \mathrm{~min}$, maintained until $11 \mathrm{~min}$, with subsequent re-equilibration at $5 \%$ for further $2.5 \mathrm{~min}$. The flow rate was $0.4 \mathrm{ml} / \mathrm{min}$.

The selected reaction monitoring (SRM) method transitions and the related parameters for T2 were set as follows. Transitions are: $525.9 \rightarrow 352.9,525.9 \rightarrow 381.8,525.9 \rightarrow 479.9 \mathrm{KDa}$; declustering potential $87.0 \mathrm{kV}$; collision energy 40.8, 27.6, and $26.0 \mathrm{kV}$, respectively; collision exit potential 10.3,11.2, and $14.2 \mathrm{kV}$, respectively. The SRM method transitions for the detection of T3 and T4 were set as described previously (17). Medium peak area at time zero was taken as reference area for the other time points.

\section{Cell Viability Test}

Cell viability was assessed by using two different assays: the 3-(4,5-dimethylthiazol-2-yl) 2,5-diphenyltetrazolium bromide (MTT) test (18) and crystal violet staining (19). Cells were seeded in 96-well microtiter plate at a density of 5,000-10,000. Twenty four hours after, T2, T3, or T4 were added at different concentrations and cell viability was determined $24 \mathrm{~h}$ after incubation. MTT $(0.5 \mathrm{mg} / \mathrm{ml})$ was added to the medium, and after an additional $4 \mathrm{~h}$ incubation, SDS- $\mathrm{HCl}(0.05 \mathrm{mg} / \mathrm{ml})$ was added to solubilize formazan salt. After $18 \mathrm{~h}$, the absorbance of the solution was read at $570 \mathrm{~nm}$ in a microplate reader (BioRad Laboratories, Italy). Since T2 is known to affect mitochondrial activity and MTT test is based on mitochondrial function, crystal violet staining was performed according to Feoktistova et al. (19) with minor modifications. Upon iodothyronine treatment, cells were washed gently with warmed PBS, then stained $10 \mathrm{~min}$ at room temperature with crystal violet solution $(0.2 \%$ crystal violet in $2 \%$ ethanol). The plate was washed twice with deionized water, and then a $1 \%$ SDS solution was added to each well, and the plate was agitated until complete solubilization of the staining that was read at $570 \mathrm{~nm}$.

\section{Isolated Heart Perfusion and Ryanodine Binding}

Experimental procedures were approved by the ethical committee of the University of Pisa (protocol no. 51814/2016). The investigation conforms with the Guide for the Care and Use of Laboratory Animals published by the US National Institutes of Health (NIH publication no. 85-23, revised 1996).

Male Wistar rats (275-300 g body weight), fed a standard diet, were anesthetized with a mixture of ether and air. The heart was then quickly excised and perfused according to the working heart technique, as described previously (17). The perfusion buffer included (mM): $\mathrm{NaCl}, 118 ; \mathrm{NaHCO}_{3}, 25 ; \mathrm{KCl}, 4.5 ; \mathrm{KH}_{2} \mathrm{PO}_{4}$, 1.2; $\mathrm{MgSO}_{4}, 1.2 ; \mathrm{CaCl}_{2}, 1.5$; glucose, 11. Perfusions were carried out using $200 \mathrm{ml}$ of recirculating buffer, which was equilibrated with a mixture of $\mathrm{O}_{2}(95 \%)$ and $\mathrm{CO}_{2}(5 \%)$. Temperature was kept between 36.8 and $37^{\circ} \mathrm{C}$, and the $\mathrm{pH}$ was 7.4. Powerlab/200
(ADInstruments, Castle Hill, Australia) was used for hemodynamic variable acquisition. The height of the atrial chamber was set at $20 \mathrm{~cm}$, corresponding to a filling pressure of $15 \mathrm{mmHg}$. During the experiment, after an equilibration period of $10 \mathrm{~min}$, T2, T3, or T4 (0.1-10 $\mu \mathrm{M})$ was added to the perfusion buffer and hearts were perfused for another $50 \mathrm{~min}$. In the control group, hearts were perfused only with standard buffer and vehicle. At the end of the perfusion, hearts treated with or without $10 \mu \mathrm{M}$ $\mathrm{T} 2$ were homogenized in five volumes of $300 \mathrm{mM}$ sucrose and $10 \mathrm{mM}$ imidazole ( $\mathrm{pH} 7.0$ at $4^{\circ} \mathrm{C}$ ) and high affinity ryanodine binding was determined on the crude homogenate (20). Briefly, vesicles were incubated at $37^{\circ} \mathrm{C}$ in a buffer containing $25 \mathrm{mM}$

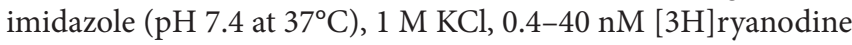
(6 Ci/mmol), $0.950 \mathrm{mM} \mathrm{EGTA}$, and $1.013 \mathrm{mM} \mathrm{CaCl}_{2}$ (free $\mathrm{Ca}^{2+}$ concentration was $20 \mu \mathrm{M}$ ). After $60 \mathrm{~min}$, the binding reaction was stopped by filtration through cellulose nitrate filters which were washed twice with $25 \mathrm{mM}$ imidazole and $1 \mathrm{M} \mathrm{KCl}$ (washing buffer). Radioactivity was counted at $60 \%$ efficiency in TRI-CARB 2800 TR Liquid Scintillation Analyzer (Perkin Elmer, Italy). Incubations were performed in duplicate and nonspecific binding was measured in the presence of $10 \mu \mathrm{M}$ unlabeled ryanodine. Saturation experiments were analyzed by nonlinear fitting of a single binding site model.

\section{Statistical Analysis}

Results are expressed as the mean \pm SEM. Differences between groups were analyzed by one-way or two-way ANOVA as detailed for each figure. In the experiments aimed at determining differences vs a single control group, Dunnett's post hoc test was applied. When the experimental setting included only two groups, statistical differences were determined by unpaired $t$-test. The threshold of statistical significance was set at $P<0.05$. GraphPad Prism version 6.0 for Windows (GraphPad Software, San Diego, CA, USA) was used for data processing and statistical analysis.

\section{RESULTS}

\section{Cellular Uptake of lodothyronines}

The results of the T2 uptake experiments in H9c2 cells are shown in Figure 1. Uptake was carried out with medium $(0.5 \mathrm{ml})$ containing $100 \mathrm{nM}$ T2 (50 pmol/well). In lysate, T2 concentration increased over time reaching a value of about $14 \mathrm{nM}(7 \mathrm{pmol} /$ well) after $24 \mathrm{~h}$, while in medium steady state concentration was reached after $6 \mathrm{~h}$, and it averaged about $110 \mathrm{nM}$ ( $55 \mathrm{pmol} /$ well). So the overall recovery of T2, after $24 \mathrm{~h}$ infusion, was slightly higher than $100 \%$. Since lysate volume was in the order of $0.02-0.03 \mathrm{ml}$, the actual cellular concentration at the end of the treatment can be estimated to be about 250-350 nM. From preliminary experiments, similar results were obtained in the presence of $50 \mathrm{nM}$ T3 or T4, whose cellular uptake after $24 \mathrm{~h}$ was on the order of 10 and $2 \%$ of the medium concentration, respectively (data not shown).

\section{Cell Viability}

After $24 \mathrm{~h}$ incubation with T2, MTT assay was carried out in H9c2 cell lines. As shown in Figure 2A, incubation with T2 at concentrations $\geq 500 \mathrm{nM}$ caused $15-16 \%$ decrease in MTT 


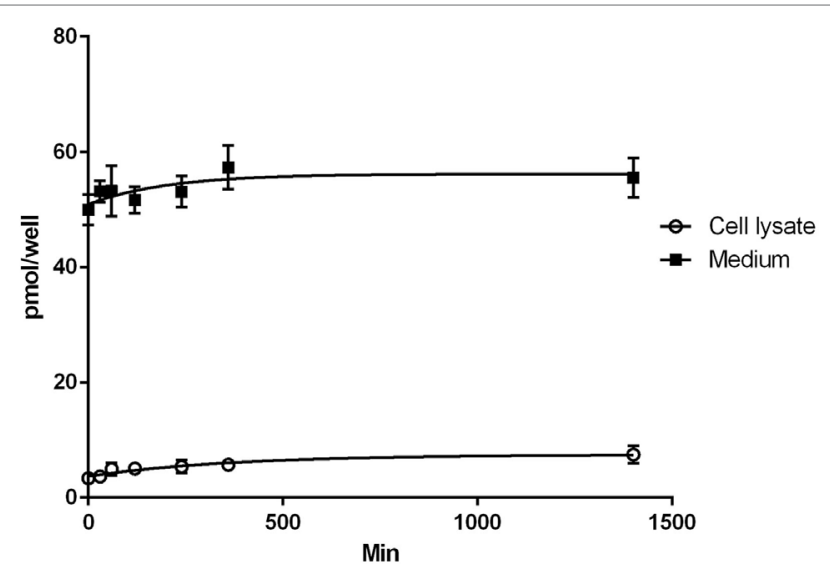

FIGURE 1 | Uptake of T2. Results of T2 uptake in H9c2 cell during $24 \mathrm{~h}$ of incubation with $100 \mathrm{nM}$ T2 in medium. Assays were performed at different times in the incubation medium and in the cell lysate. Values are mean \pm SEM of results derived from three uptake experiments.

staining, compared to vehicle $(P<0.05$ by one-way ANOVA test and Dunnett's post hoc). This may imply decreased cell viability (and/or reduced oxidative metabolism). To get a better insight, we also performed crystal violet staining. Crystal violet binds to DNA and proteins of cells that did not lose their adherence, and is considered as an alternative index of viability. As shown in Figure 2C, crystal violet staining was reduced $(P<0.05)$ only at the highest $\mathrm{T} 2$ concentration $(10 \mu \mathrm{M})$, whereas it was not affected by equimolar T3 or T4 and it was actually increased in the presence of $0.1 \mu \mathrm{M}$ T3 $(P<0.05$ vs control). Similar results were obtained in MTT staining by T3 $(P<0.050 .1 \mu \mathrm{M}$ vs control), while $10 \mu \mathrm{M}$ T4 significantly reduced cell viability by $33 \%$ $(P<0.001$ vs control, Figure $2 B)$.

\section{Glucose Consumption and Hexokinase Activity}

To assess glucose consumption, $\mathrm{H} 9 \mathrm{c} 2$ cells were incubated for $4 \mathrm{~h}$ in phenol red-free DMEM containing $0.7 \mathrm{~g} / \mathrm{l}$ glucose, as described in Section "Materials and Methods." At the end of treatment, glucose concentration was assayed in the medium and the results were expressed as the difference between the initial and final concentrations, and normalized to the total protein content of cell lysates. As shown in Figure 3A, T2 caused a $23-30 \%$ increase in glucose consumption if administered at the concentrations of 0.1 or $1 \mu \mathrm{M}(P<0.05$ vs control by oneway ANOVA test and Dunnett's test), by a mechanism which does not involve hexokinase, as revealed by enzymatic activity being unaffected by T2 (Figure 3D). At $10 \mu \mathrm{M}$ T2 concentration, glucose consumption was also enhanced, but the difference vs control did not reach statistical significance $(0.066 \pm 0.003$ vs $0.055 \pm 0.003 \mathrm{mg}$ glucose $/ \mathrm{mg}$ protein, $P=\mathrm{NS}$ ). By comparison, glucose consumption was not affected by $0.1-10 \mu \mathrm{M}$ T3 (Figure 3B), while it was significantly reduced in cell exposed to $1-10 \mu \mathrm{M} \mathrm{T} 4$, by 24 and $41 \%$, respectively $(P<0.05$ and $P<0.001$, respectively; see Figure 3C).

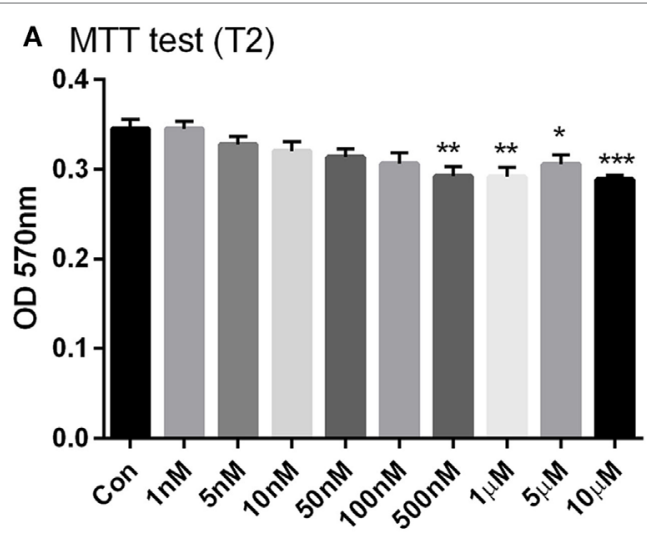

B MTT test (T3 and T4)

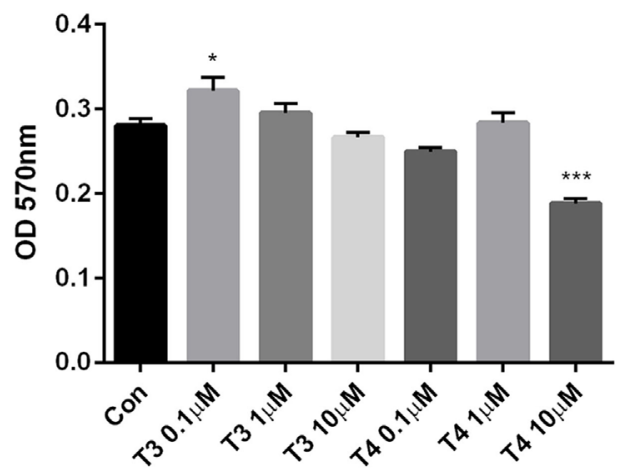

C Crystal violet staining

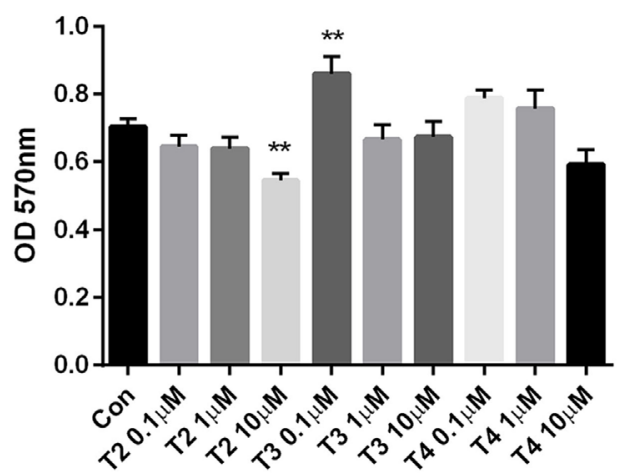

FIGURE 2 | Cell viability. H9c2 cells were incubated for $24 \mathrm{~h}$ with a wide range of $\mathrm{T} 2(1 \mathrm{nM}-10 \mu \mathrm{M}), \mathrm{T} 3$, and $\mathrm{T} 4(0.1-10 \mu \mathrm{M})$ concentrations in medium incubation and then the cell viability tests, MTT test $(\mathbf{A}, \mathbf{B})$, and crystal violet assay (C) were performed. All treatments received the same amount of vehicle. Control group was incubated with medium containing the same volume of vehicle. Data are plotted as means of 4-6 replicas \pm SEM [oneway ANOVA, $P<0.0001$, Dunnett's post hoc test for multiple comparison, ${ }^{\star} P<0.05,{ }^{\star \star} P<0.01,{ }^{\star \star \star} P<0.001$ vs control (con), $n=4-6$ per group].

\section{Heart Perfusion and Ryanodine Binding}

The results of the perfusion experiments are shown in Figure 4. Baseline values of the hemodynamic variables averaged as follows: aortic flow (AF) $37.3 \pm 0.6 \mathrm{ml} / \mathrm{min}$, coronary flow (CF) $19.3 \pm 0.6 \mathrm{ml} / \mathrm{min}$, cardiac output $(\mathrm{CO}) 56.7 \pm 0.7 \mathrm{ml} / \mathrm{min}$, 

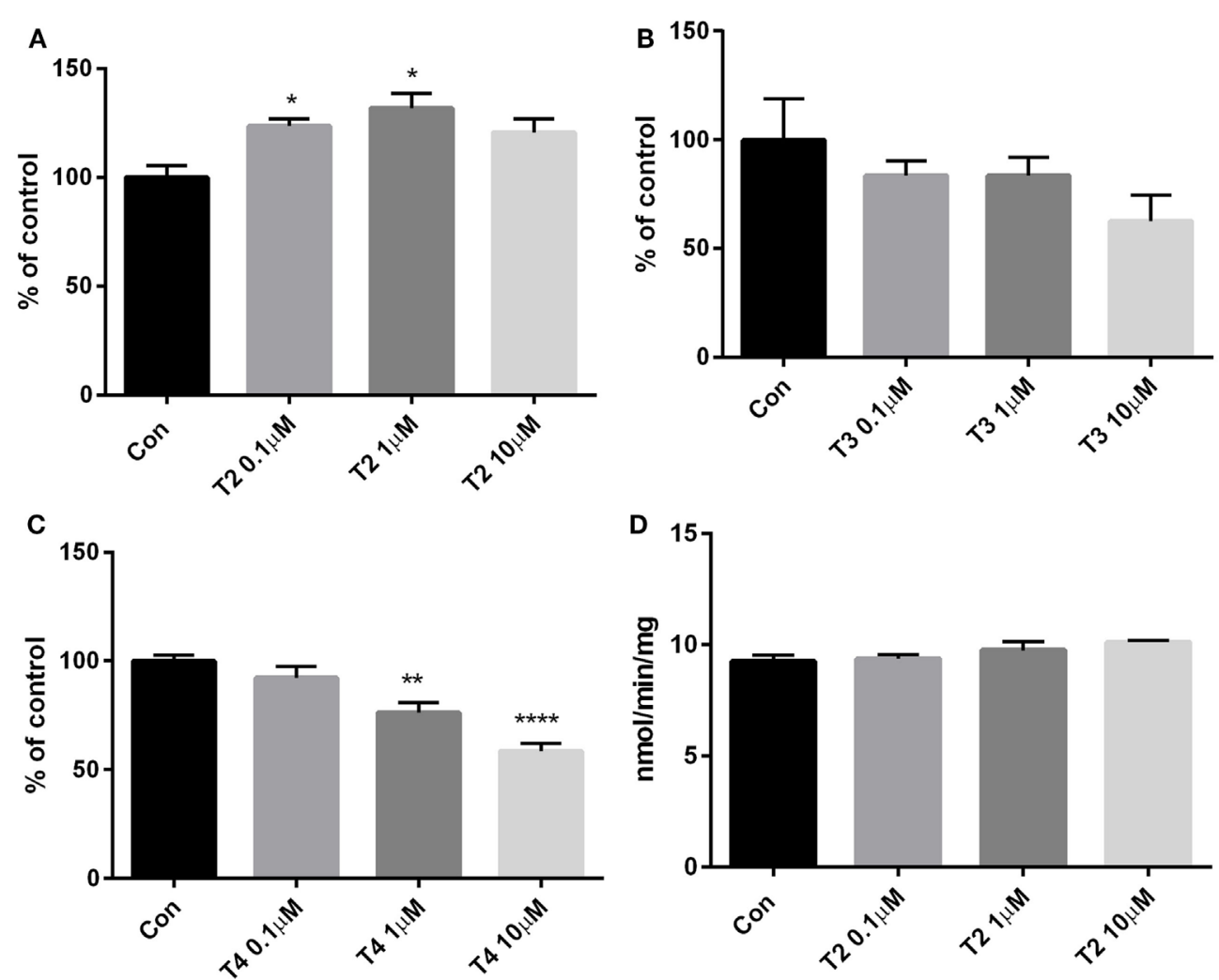

FIGURE 3 | Glucose consumption and hexokinase activity. Glucose concentration was assayed in cell medium after $4 \mathrm{~h}$ treatment with (A) T2, (B) T3, or (C) T4 $(0.1-10 \mu \mathrm{M})$. Results are the difference between the initial glucose concentration in medium $(0.707 \mathrm{mg} / \mathrm{ml}$, assessed with the glucose assay kit) and the final concentration, normalized to the total content of protein in lysate. Control cells were incubated with medium containing the same volume of vehicle. (D) Hexokinase activity assay was performed in cell lysates upon treatment with T2. Values are mean \pm SEM of 3-4 replicates and are expressed as percent of control in the glucose consumption or as NADH nmol/min/mg in the enzyme activity. [one-way ANOVA, $P<0.05$, Dunnett's post hoc test for multiple comparison, ${ }^{\star} P<0.05$, ${ }^{* \star} P<0.01$ vs control (con), $n=3-4$ per groups].

heart rate (HR) $215.6 \pm 9.8$ beats/min, and peak systolic aortic pressure (PAP) $182.8 \pm 6.8 \mathrm{mmHg}$. T2 $(0.1-10 \mu \mathrm{M})$ was added $10 \mathrm{~min}$ after the beginning of the perfusion, and hearts were perfused for another $50 \mathrm{~min}$ with $\mathrm{T} 2$, while in the control group the same amount of vehicle was added. After 20 min of perfusion with $10 \mu \mathrm{M}$ T2, a slight but significant reduction was observed in $\mathrm{CO}$ and in $\mathrm{AF}$ (AF: $-10-12 \%$ at $20-40 \min P<0.05$; CO: 9-10\% at 20-30 $\min P<0.05$; see Figures $4 \mathrm{~A}, \mathrm{C}$ ). The other hemodynamic variables, namely the CF, HR, and PAP were not affected by $\mathrm{T} 2$ perfusion (Figures $4 \mathrm{~B}, \mathrm{D}, \mathrm{E}$ ). As a comparison, perfusions with $0.1,1$, and $10 \mu \mathrm{M}$ T3 or T4 did not produce any significant changes in contractile performance (Figures $4 \mathbf{F}-\mathbf{H}$, $\mathrm{AF}, \mathrm{CF}$, and $\mathrm{CO}$ ).

In ryanodine binding experiments, crude homogenates of hearts perfused with $10 \mu \mathrm{M}$ T2 were analyzed. We explored only the concentration that affected, albeit only transiently, the CO. As shown in Figure 5, T2 did not modify ryanodine binding: either the number of binding sites (Figure 5A) or the affinity for ryanodine (Figure 5B) were unchanged by T2 perfusion (Bmax averaged $107.0 \pm 7.9$ vs $119.7 \pm 7.3 \mathrm{fmol} /$ $\mathrm{mg}$; Kd averaged $0.45 \pm 0.14$ vs $0.54 \pm 0.16 \mathrm{nM}, P=\mathrm{NS}$ in all cases).

\section{DISCUSSION}

T2 is a putative derivative of the TH whose effects on lipid metabolism are well established. On the contrary, the cardiac actions of T2 are less known and still controversial. In the present work, we analyzed the effects of T2 on cardiac tissue in perfused rat hearts and $\mathrm{H} 9 \mathrm{c} 2$ cell cultures, using equimolar dosages of T3 and T4 as a control.

We observed that T2 can be taken up and accumulated in cardiomyoblasts. T2 was rapidly absorbed, since its presence was detected in cell lysate after a few minutes of incubation, with a complete recovery after $24 \mathrm{~h}$, suggesting that no T2 catabolites were produced under these experimental conditions, although additional investigations are needed to verify this hypothesis. At the end of the treatment, cell lysate concentration was estimated to average about 250-350 nM, exceeding the medium concentration by over 2-3-fold. Either MCT8 or MCT10 might be responsible for $\mathrm{T} 2$ uptake, since these transporters are relatively nonspecific for iodothyronines (21). However the molecular identity of T2 transporters is still unknown.

The absence of significant T2 catabolism is consistent with the fact that rat cardiomyocytes, and in general rodent 

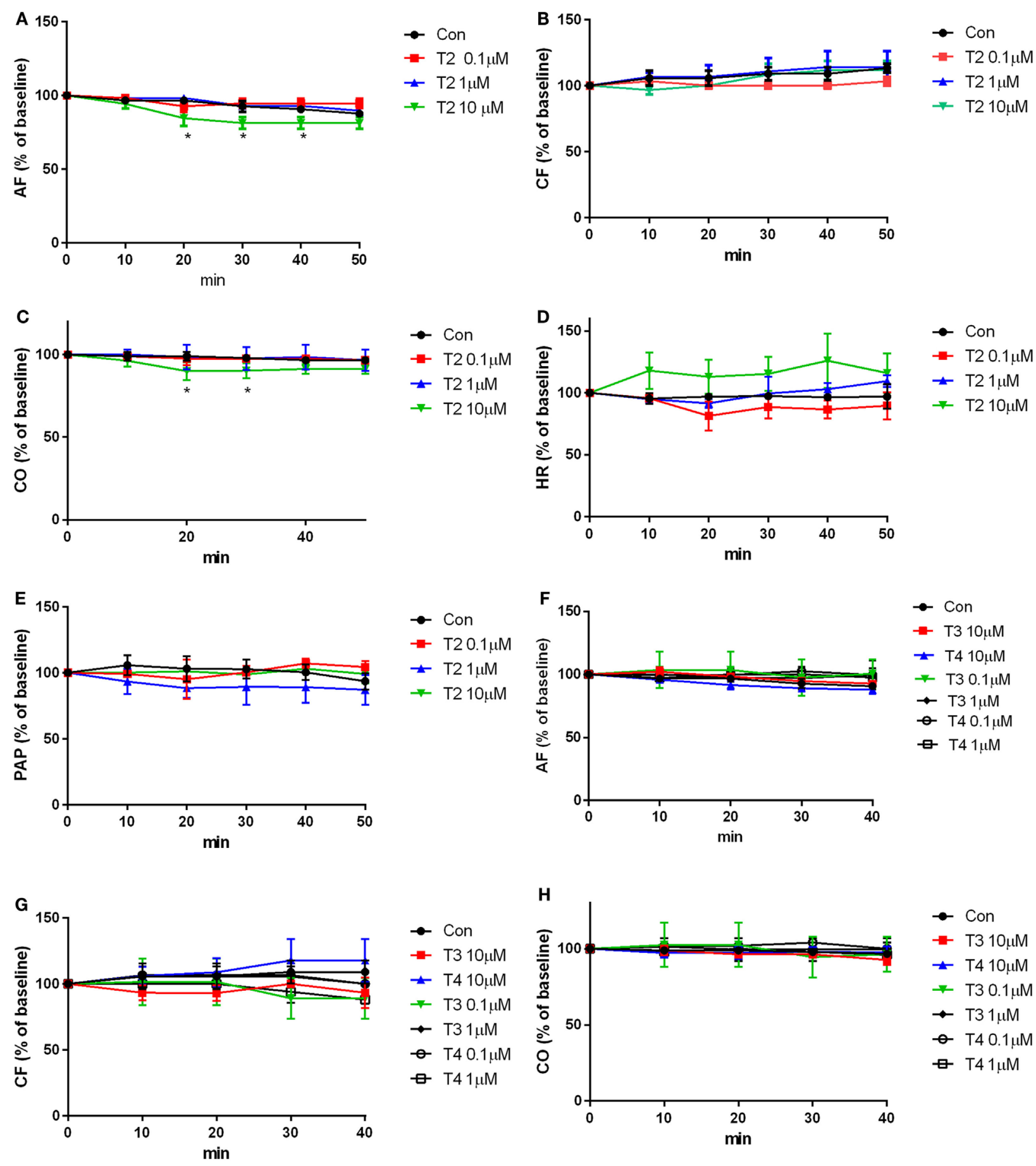

FIGURE 4 | Contractile performance. Heart was perfused for 50 min with buffer containing the vehicle or iodothyronines $(0.1-10 \mu M)$. Hemodynamic variables were measured every $10 \mathrm{~min}$ of perfusion and are expressed as percentage of the basal values, that were measured after 10 min of perfusion, i.e., before any addition to the perfusion buffer supplemented with $(\mathbf{A}-\mathbf{E}) \mathrm{T} 2$, (F-H) T3, (F-H) T4, or vehicle. Results represent mean \pm SEM of three hearts per group. $\left[{ }^{\star} P<0.05\right.$ for the effect of treatment, by two-way ANOVA, Dunnett's post hoc test for multiple comparison, ${ }^{\star} P<0.05$ vs control (con), $n=3$ per groups]. Abbreviations: AF, aortic flow; CF, coronary flow; CO, cardiac output; HR, heart rate; PAP, peak systolic aortic pressure.

hearts, express low concentration of type II deiodinase, which has higher affinity for T3 and T4 than type I deiodinase (22). Although type III deiodinases might be more abundant in cadiomyoblasts, considering their fetal origin and capacity of proliferation (type III deiodinase expression is correlated to proliferative activity and pluripotency) (22), their effect appeared to be negligible. We cannot exclude that T2 catabolism might be balanced by local production, since H9c2 cell line 


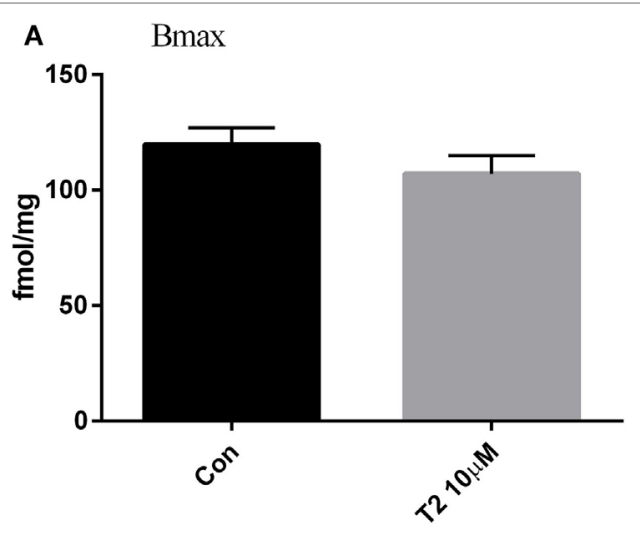

B

$\mathrm{Kd}$

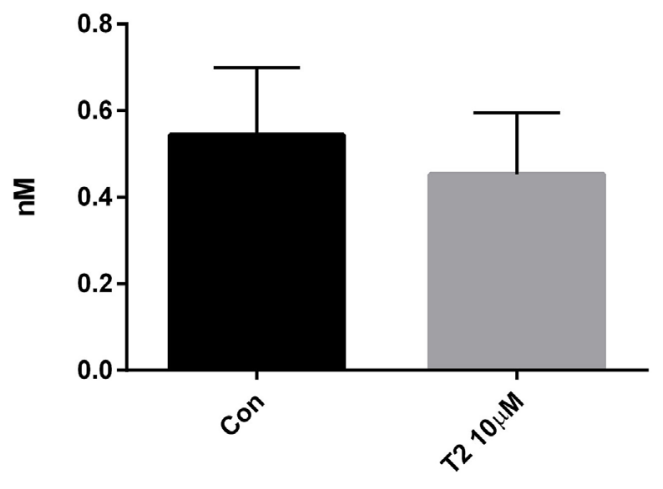

FIGURE 5 | Ryanodine binding. Effect of T2 on the density of ryanodine binding sites [Bmax, fmol/mg, (A)] and affinity for ryanodine [Kd, nM, (B)] in crude cardiac homogenates. Ryanodine binding was determined in ventricle homogenate after 50 min of perfusion. Histograms represent mean \pm SEM derived from three hearts per group. Unpaired $t$-test yielded $P=$ ns for the difference between groups.

have been reported to produce low levels of TH in an appropriate environment (23).

The glucose consumption results showed that T2 increased cardiomyocyte glucose uptake, as already demonstrated in skeletal muscle by Moreno et al. (12), who have described an increase in myofiber glycolytic activity. Consistently, T2 has been reported to be able to increase GLUT4 concentrations on plasma membrane, by increasing AKT phosphorylation by insulin (12). This might suggest that the higher glucose uptake was a consequence of an increase in glycolytic flow, even though the hexokinase activity was not influenced by T2, as revealed by enzymatic assay. The latter appears to be a primary metabolic effect, since the hemodynamic variables were not modified, and the energy need for contraction was, therefore, putatively unchanged, as confirmed also by the absence of changes in sarcoplasmic reticulum calcium channels.

As to the underlying molecular mechanism, the relatively short time course of our experiments $(1-4 \mathrm{~h})$ does not suggest the occurrence of genomic effects. This is consistent with several previous studies [reviewed by Moreno et al. (24)], and with the observation that $\mathrm{T} 2$ has a low affinity for nuclear $\mathrm{TH}$ receptors (25), and in any case it is relatively selective for TR beta, while TR alpha is the predominant cardiac isoform $(26,27)$. On the whole, it is likely that T2 activates short-term mechanisms, acting directly on specific protein targets, possibly located in mitochondria (28).

In vitro viability tests indicated that $\mathrm{T} 2$ produced only minor toxic effects upon a chronic $(24 \mathrm{~h})$ treatment. MTT staining was slightly but significantly reduced at concentrations exceeding $500 \mathrm{nM}$. Since the MTT test depends on mitochondrial function, we also used the crystal violet assay, finding out some evidence of $\mathrm{T} 2$ toxicity only at the highest concentration $(10 \mu \mathrm{M})$. As reported (19), crystal violet is a stain for viable adherent cells, able to bind to proteins and DNA. Cells undergoing cell death lose their adherence and are subsequently lost from the population of cells, reducing the amount of staining in cell culture. So, the decreased MTT staining observed at lower concentrations may be related to a reduced oxidative metabolism due to changes in mitochondrial function. On the other hand, the toxic effect was not reproduced by equimolar T3 and T4, and interestingly $10 \mu \mathrm{M}$ T2, but not equimolar $\mathrm{T} 3$ or $\mathrm{T} 4$, produced a slight and temporary reduction of the $\mathrm{CO}$ in the isolated working rat heart model.

Our experimental findings are consistent with the clinical results reported by Antonelli et al. (14) upon a 4-week treatment $(300 \mu \mathrm{g} /$ day $)$ in healthy volunteers: T2 decreased body weight, and enhanced resting metabolic rate without affecting cardiac contractility. On the contrary, Jonas et al. (15) observed that T2 induced cardiac hypertrophy in mice after 2 weeks of treatment at $2.5 \mu \mathrm{g} / \mathrm{g}$.

Differences in T2 concentration are a crucial issue, potentially able to account for these discrepancies. The T2 dosages used in previous studies (28-31) were widely different, namely 0.1-100 nM (29), $10 \mathrm{nM}$ (28), 0.01-10 $\mu \mathrm{M}$ (31), or $1-10 \mu \mathrm{M}$ (30). Different serum levels have also been measured: depending on the assay method applied to quantify T2, its circulating concentration ranged from $20-50$ to $400-500$ pM (32-38). Higher serum concentrations $(50-400 \mathrm{nM})$ were measured by Jonas et al. (15) in mice treated for 14 days with $0.25-2.5 \mu \mathrm{g} / \mathrm{g}$ $\mathrm{T} 2$. Interestingly $10 \mu \mathrm{M} \mathrm{T} 2$, the highest dosage reported in in vitro studies $(30,31)$ was the only one for which a slightly cytotoxicity was observed in our cell line.

In conclusion, our findings show that $\mathrm{T} 2$ can increase cardiac glucose consumption even though the contractile performance was unchanged. In our model, only minimal toxic effects were observed, at concentrations substantially higher than those associated with metabolic effects. So far, T2 serum concentration has not been accurately assessed, and further investigations will be needed to develop, standardize, and validate appropriate analytical methods. Once endogenous T2 levels are determined, it will be possible to investigate its potential physiological, pathophysiological, or pharmacological relevance for the heart and other tissues.

\section{DATA AVAILABILITY STATEMENT}

Datasets are available on request. The raw data supporting the conclusions of the manuscript will be made available by the authors, without undue reservation, to any qualified researcher.

\section{ETHICS STATEMENT}

Experimental procedures were approved by the ethical committee of the University of Pisa (protocol no. 51814/2016, for organ 
explants). The investigation conforms with the Guide for the Care and Use of Laboratory Animals published by the US National Institutes of Health (NIH publication no. 85-23, revised 1996).

\section{AUTHOR CONTRIBUTIONS}

GS, MN, and LL designed and carried out cell culture experiments. SF performed the ex vivo experiments on heart.

\section{REFERENCES}

1. Goglia F. Biological effects of 3,5-diiodothyronine (T2). Biochemistry (Mosc) (2005) 70(2):164-72. doi:10.1007/s10541-005-0097-0

2. Moreno M, Lombardi A, Beneduce L, Silvestri E, Pinna G, Goglia F, et al. Are the effects of $\mathrm{T} 3$ on resting metabolic rate in euthyroid rats entirely caused by T3 Itself? Endocrinology (2002) 143(2):504-10. doi:10.1210/endo. 143.2.8613

3. Moreno M, Lanni A, Lombardi A, Goglia F. How the thyroid controls metabolism in the rat: different roles for triiodothyronine and diiodothyronines. J Physiol (1997) 505:529-38. doi:10.1111/j.1469-7793.1997.529bb.x

4. Moreno M, Lange PD, Lombardi A, Silvestri E, Lanni A, Goglia F. Metabolic effects of thyroid hormone derivatives. Thyroid (2008) 18(2):239-53. doi:10.1089/thy.2007.0248

5. O'reilly I, Murphy MP. Studies on the rapid stimulation of mitochondrial respiration by thyroid hormones. Acta Endocrinol (Copenh) (1992) 127(6): 542-6. doi:10.1530/acta.0.1270542

6. Cimmino M, Mion F, Goglia F, Minaire Y, Geloen A. Demonstration of in vivo metabolic effects of 3,5-di-iodothyronine. J Endocrinol (1996) 149(2):319-25. doi:10.1677/joe.0.1490319

7. Lanni A, Moreno M, Lombardi A, Goglia F. Rapid stimulation in vitro of rat liver cytochrome oxidase activity by 3,5-diiodo-L-thyronine and by $3,3^{\prime}$-diiodo-L-thyronine. Mol Cell Endocrinol (1994) 99(1):89-94. doi:10.1016/ 0303-7207(94)90150-3

8. Lombardi A, Lanni A, Moreno M, Brand DM, Goglia F. Effect of 3,5-di-iodoL-thyronine on the mitochondrial energy-transduction apparatus. Biochem J (1998) 330(1):521-6. doi:10.1042/bj3300521

9. Ball SG, Sokolov J, Chin WWJ. 3,5-Diiodo-L-thyronine (T2) has selective thyromimetic effects in vivo and in vitro. Mol Endocrinol (1997) 19(2):137-47. doi:10.1677/jme.0.0190137

10. Lanni A, Moreno M, Lombardi A, de Lange P, Silvestri E, Ragni M, et al. 3,5-Diiodo-L-thyronine powerfully reduces adiposity in rats by increasing the burning of fats. FASEB J (2005) 19:1552-4. doi:10.1096/fj.05-3977fje

11. de Lange P, Cioffi F, Senese R, Moreno M, Lombardi A, Silvestri E, et al. Nonthyrotoxic prevention of diet-induced insulin resistance by 3,5-Diiodo-L-thyronine in rats. Diabetes (2011) 60(11):2730-9. doi:10.2337/ db11-0207

12. Moreno M, Silvestri E, De Matteis R, de Lange P, Lombardi A, Glinni D, et al. 3,5-Diiodo-L-thyronine prevents high-fat-diet-induced insulin resistance in rat skeletal muscle through metabolic and structural adaptations. FASEB J (2011) 25(10):3312-24. doi:10.1096/fj.11-181982

13. Lombardi A, Lanni A, de Lange P, Silvestri E, Grasso P, Senese R, et al. Acute administration of 3,5-diiodo-L-thyronine to hypothyroid rats affects bioenergetic parameters in rat skeletal muscle mitochondria. FEBS Lett (2007) 581(30):5911-6. doi:10.1016/j.febslet.2007.11.073

14. Antonelli A, Fallahi P, Ferrari SM, Di Domenicantonio A, Moreno M, Lanni A, et al. 3,5-Diiodo-L-thyronine increases resting metabolic rate and reduces body weight without undesirable side effects. J Biol Regul Homeost Agents (2011) 25(4):655-60.

15. Jonas W, Lietzow J, Wohlgemuth F, Hoefig CS, Wiedmer P, Schweizer U, et al. 3,5-Diiodo-L-thyronine (3,5-T2) exerts thyromimetic effects on hypothalamuspituitary-thyroid axis, body composition, and energy metabolism in male diet-induced obese mice. Endocrinology (2015) 156(1):389-99. doi:10.1210/ en.2014-1604

16. Bradford MM. A rapid and sensitive method for the quantification of microgram quantities of protein utilizing the principle of protein-dye binding. Anal Biochem (1976) 72:248-54. doi:10.1016/0003-2697(76)90527-3
AS carried out mass spectrometry measurements. RZ revised the manuscript and performed statistical analysis. SG designed and supervised the experimental work and wrote the manuscript.

\section{FUNDING}

This work was supported by University of Pisa, Pisa, Italy.

17. Saba A, Chiellini G, Frascarelli S, Marchini M, Ghelardoni S, Raffaelli A, et al. Tissue distribution and cardiac metabolism of 3-iodothyronamine. Endocrinology (2010) 151:5063-73. doi:10.1210/en.2010-0491

18. Mosmann T. Rapid colorimetric assay for cellular growth and survival: application to proliferation and cytotoxicity assays. J Immunol Methods (1983) 65:55-63. doi:10.1016/0022-1759(83)90303-4

19. Feoktistova M, Geserik P, Leverkus M. Crystal violet assay for determining viability of cultured cells. Cold Spring Harb Protoc (2016) 2016(4):db. rot087379. doi:10.1101/pdb.prot087379

20. Ghelardoni S, Chiellini C, Frascarelli S, Zucchi R. Cardioprotection by ranolazine in perfused rat heart. J Cardiovasc Pharmacol (2014) 64(6):507-13. doi:10.1097/FJC.0000000000000144

21. Heuer H, Visser TJ. Minireview: pathophysiological importance of thyroid hormone transporters. Endocrinology (2009) 150(3):1078-83. doi:10.1210/ en.2008-1518

22. Jansen R, Muller A, Simonides WS. Cardiac thyroid hormone metabolism and heart failure. Eur Thyroid J (2017) 6(3):130-7. doi:10.1159/000469708

23. Meischl C, Buermans HP, Hazes T, Zuidwijk MJ, Musters RJ, Boer C, et al. H9c2 cardiomyoblasts produce thyroid hormone. Am J Physiol Cell Physiol (2008) 294(5):C1227-33. doi:10.1152/ajpcell.00328.2007

24. Moreno M, Giacco A, Di Munno C, Goglia F. Direct and rapid effects of 3,5-diiodo-L-thyronine (T2). Mol Cell Endocrinol (2017) 15(458):121-6. doi:10.1016/j.mce.2017.02.012

25. Padron AS, Neto RA, Pantaleão TU, de Souza dos Santos MC, Araujo RL, de Andrade BM, et al. Administration of 3,5-diiodothyronine (3,5-T2) causes central hypothyroidism and stimulates thyroid-sensitive tissues. $J$ Endocrinol (2014) 221(3):415-27. doi:10.1530/JOE-13-0502

26. Mendoza A, Navarrete-Ramírez P, Hernández-Puga G, Villalobos P, Holzer G, Renaud JP, et al. 3,5-T2 is an alternative ligand for the thyroid hormone receptor $\beta 1$. Endocrinology (2013) 154(8):2948-58. doi:10.1210/en.2013-1030

27. White P, Dauncey MJ. Differential expression of thyroid hormone receptor isoforms is strikingly related to cardiac and skeletal muscle phenotype during postnatal development. J Mol Endocrinol (1999) 23(2):241-54. doi:10.1677/ jme.0.0230241

28. Rutigliano G, Zucchi R. Cardiac actions of thyroid hormone metabolites. Mol Cell Endocrinol (2017) 15(458):76-81. doi:10.1016/j.mce.2017.01.003

29. Del Viscovo A, Secondo A, Esposito A, Goglia F, Moreno M, Canzoniero LM. Intracellular and plasma membrane-initiated pathways involved in the $[\mathrm{Ca} 2+]$ i elevations induced by iodothyronines (T3 and T2) in pituitary GH3 cells. Am J Physiol Endocrinol Metab (2012) 302(11):E1419-30. doi:10.1152/ ajpendo.00389.2011

30. Gnocchi D, Massimi M, Alisi A, Incerpi S, Bruscalupi G. Effect of fructose and 3,5-diiodothyronine (3,5-T(2)) on lipid accumulation and insulin signalling in non-alcoholic fatty liver disease (NAFLD)-like rat primary hepatocytes. Horm Metab Res (2014) 46(5):333-40. doi:10.1055/s-0034-1371858

31. Grasselli E, Voci A, Canesi L, Salis A, Damonte G, Compalati AD, et al. 3,5-Diiodo-L-thyronine modifies the lipid droplet composition in a model of hepatosteatosis. Cell Physiol Biochem (2014) 33(2):344-56. doi:10.1159/ 000356674

32. Rochira A, Damiano F, Marsigliante S, Gnoni GV, Siculella L. 3,5-Diiodo-1thyronine induces SREBP-1 proteolytic cleavage block and apoptosis in human hepatoma (Hepg2) cells. Biochim Biophys Acta (2013) 1831(12):1679-89. doi:10.1016/j.bbalip.2013.08.003

33. Pinna G, Meinhold H, Hiedra L, Thoma R, Hoell T, Gräf KJ, et al. Elevated 3,5-diiodothyronine concentrations in the sera of patients with nonthyroidal illnesses and brain tumors. J Clin Endocrinol Metab (1997) 82(5):1535-42. doi:10.1210/jcem.82.5.3939 
34. De Angelis M, Giesert F, Finan B, Clemmensen C, Müller TD, Vogt-Weisenhorn D, et al. Determination of thyroid hormones in mouse tissues by isotopedilution microflow liquid chromatography-mass spectrometry method. J Chromatogr B Analyt Technol Biomed Life Sci (2016) 15(1033-1034):413-20. doi:10.1016/j.jchromb.2016.08.037

35. Hansen M, Luong X, Sedlak DL, Helbing CC, Hayes T. Quantification of 11 thyroid hormones and associated metabolites in blood using isotopedilution liquid chromatography tandem mass spectrometry. Anal Bioanal Chem (2006) 408(20):5429-42. doi:10.1007/s00216-016-9614-9

36. Dietrich JW, Müller P, Schiedat F, Schlömicher M, Strauch J, Chatzitomaris A, et al. Nonthyroidal illness syndrome in cardiac illness involves elevated concentrations of 3,5-diiodothyronine and correlates with atrial remodeling. Eur Thyroid J (2015) 4(2):129-37. doi:10.1159/ 000381543

37. Lehmphul I, Brabant G, Wallaschofski H, Ruchala M, Strasburger CJ, Köhrle $\mathrm{J}$, et al. Detection of 3,5-diiodothyronine in sera of patients with altered thyroid status using a new monoclonal antibody-based chemiluminescence immunoassay. Thyroid (2014) 24(9):1350-60. doi:10.1089/thy.2013.0688

38. Accorroni A,SaponaroF,Zucchi R. Tissuethyroidhormones and thyronamines. Heart Fail Rev (2016) 21(4):373-90. doi:10.1007/s10741-016-9553-8

Conflict of Interest Statement: The authors declare that the research was conducted in the absence of any commercial or financial relationships that could be construed a potential conflict of interests.

Copyright (c) 2018 Sacripanti, Nguyen, Lorenzini, Frascarelli, Saba, Zucchi and Ghelardoni. This is an open-access article distributed under the terms of the Creative Commons Attribution License (CC BY). The use, distribution or reproduction in other forums is permitted, provided the original author(s) and the copyright owner are credited and that the original publication in this journal is cited, in accordance with accepted academic practice. No use, distribution or reproduction is permitted which does not comply with these terms. 